\title{
Does the chemistry of fungal pigments demand the existence of photoactivated defense strategies in basidiomycetes?
}

\author{
Bianka Siewert ${ }^{1}$ (D) \\ Received: 10 December 2020 / Accepted: 4 March 2021 / Published online: 18 March 2021 \\ (c) The Author(s) 2021
}

\begin{abstract}
The well-known photosensitizers hypericin, harmane, and emodin are typical pigments of certain mushroom species-is this a coincidence or an indication towards a photoactivated defense mechanism in the phylum Basidiomycota? This perspective article explores this hypothesis by cross-linking the chemistry of fungal pigments with structural requirements from known photosensitizers and insights from photoactivated strategies in the kingdom Plantae. Thereby, light is shed on a yet unexplored playground dealing with ecological questions, photopharmaceutical opportunities, and biotechnological potentials.
\end{abstract}

\section{Introduction}

Whenever insects nibble on fruiting bodies of the green Cortinarius austrovenetus, the bite site turns red-violet [1]. The chemistry behind it is as easy as it is fascinating: Hypericin is formed by oxidation from the fungal pigment austrovenetin as soon as the fungal tissue is damaged [2]. Despite this striking observation, photoactivity of other fungal secondary metabolites has not yet been studied. Nevertheless, is it possible that the second kingdom with immobile reproducing structures has also evolved photochemical defense strategies to protect their fruiting bodies (Fig. 1)?

This perspective article demonstrates that several fungal pigments are phototoxic compounds and addresses the similarities between herbal and fungal defense strategies. Furthermore, the following principal questions are discussed: (A) is phototoxicity a possible ecological function of fungal pigments, and (B) could fungal pigments be hit or lead-structures for photosensitizers used in photodynamic therapy (PDT) and/or photodynamic antimicrobial chemotherapy (PACT)?

Bianka Siewert

bianka.siewert@uibk.ac.at

1 Institute of Pharmacy/Pharmacognosy and Center for Molecular Biosciences Innsbruck (CMBI), University of Innsbruck, Innsbruck, Austria

\section{The photochemistry behind light-activated defense strategies}

That sunlight is not only a key factor in the primary metabolism of plants but also a cofactor in the light-activated plant defense is an established scientific fact since the second half of the last century [3]. Responsible secondary plant metabolites are frequently reviewed [4-6]. The principle behind light-activated strategies is based on pigments, which harvest photons energy and generate lethal signals out of it [7]. In short, four different types of lethal signals might be formed: (A) a radical form of the molecule itself, (B) singlet oxygen, (C) a configurational isomer (cis/trans), or (D) a photochemically formed new chemical entity [4].

The responsible pigments, or so-called photosensitizers, occur either genuine, as precursors, or in plant tissues hidden from the sun. The roots of the nematode-resistant banana (Musacea) cultivar Yangambi km5 turn-similar to the bite marks on C. austroventus - immediately red if infested by nematodes [8]. While the chemistry behind this is based on another chemical backbone (i.e., a phenalenone-type PS, 50), the mode-of-action itself is similar: both PSs can produce lethal radical oxygen species $\left({ }^{1} \mathrm{O}_{2}\right.$ and ROS $)$ in the fungi/herbivore $[9,10]$.

The stimulated production of the phenalenone in the banana roots is representative of an induced (photo)defense mechanism [11]. This contrasts the constitutive defense mechanism, where the effector molecule is permanently present-e.g., the bitter-tasting sesquiterpenoid $\mathrm{O}$-acetylcyclocalopin A in the bitter beech bolete (Boletus calopus) $[12,13]$. The production of hypericin by the fungus 


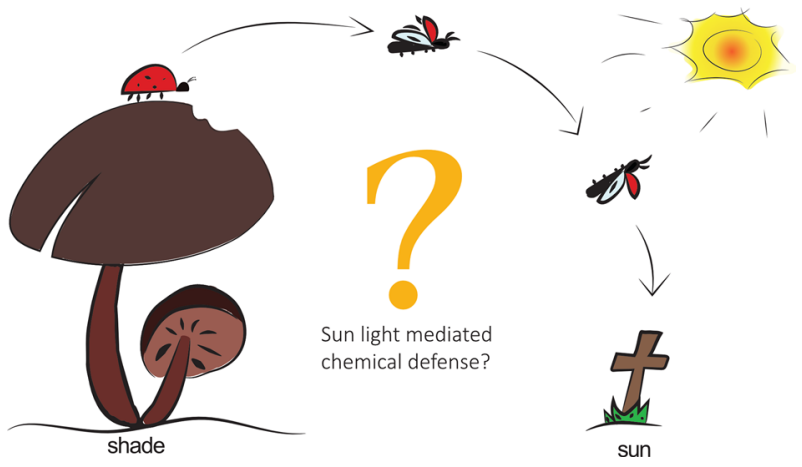

Fig. 1 The working hypothesis

C. austrovenetus represents the so-called wound-induced defense mechanism, a hybrid version of induced and constitutive defense mechanism, as the precursor of hypericin, i.e., austrovenetin, is permanently present [2]. In addition, a fourth modus is known: The attraction of predators' enemies by signaling molecules-i.e., indirect defense [14]. However, in the context of photochemical defense strategies, only the first three defense mechanisms-induced, constitutive, and wound-induced-are relevant.

\section{The chemistry of photoactivated defense}

Photoactive secondary metabolites from plants cover a variety of absorption ranges and chemical scaffolds: from the UV light-activated polyacetylenes (1), thiophenes (2), and furanocoumarins, over the yellowish alkaloids (4), guaiazulenes (5), pteride (7), curcumins, and phenalenones (47) to the higher wavelength absorbing substituted anthraquinones (8), perylene quinones (11), and porphyrins [4, 5, 7, 15].

Except for porphyrins and furanocoumarins, all photoactive chemical scaffolds of plant metabolites-sometimes even the herbal PS-are also fungal pigments (Fig. 2). In the following, the chemical classes are described, and their fungal analogs are discussed in more detail.

\subsection{Polyacetylenes and thiophenyls}

According to Marchant and Cooper [16] polyacetylenes with at least three conjugated triple bonds are putative phototoxic against microbes, nematodes, or mosquitos. Highly active representatives are conjugated further with resonance donating functional groups, such as phenyl groups or alkene functions. Most of the known photoactive polyacetylenes were isolated from Asteraceae species up to now [16]. Examples are the compounds $\mathbf{1}$ and 12-15 displayed in Fig. 3.

Several polyacetylenes were also isolated from Basidiomycota $[17,18]$ despite their general instability [19]. They are produced by the fungal genera Lepista [20], Clitocybe
[21], or Marasmius [22], which all form fleshy fruiting bodies. The chemical homology between fungal and herbal polyacetylenes is promising (Fig. 3): Trans-dehydromatricaria ester (1) originally derived from the roots of goldenrods (Solidago spp. [23].) was shown to also be an excrete of the wood-decomposing and pluriannual fruiting bodies of Daedalea juniperina [24] and a component of the long-living corky fruiting bodies of agarikon (Laricifomes officinalis) [25]. The pure compound 1 exhibited phototoxicity [26] (black light bulb, $20 \mathrm{~W}$ ) against Candida albicans.

Other known fungal polyacetylenes containing three triple bonds are C8-triynedioic acid (17) isolated from the culture broth of Poria cocos (synonym Wolfiporia extensa) [27], bioformin (16) identified in the broth of Trametes pubescens [28], or the amide $\mathbf{1 8}$ which is produced by Baeospora myosura [29]. Tetra-acetylenic metabolites, such as 19 [30], were even isolated from Mycena viridimarginata. This metabolite is, to some extent, similar to the phototoxic tetrayne 15 from bidens, e.g., Bidens hawaiensis [31].

In general, polyacetylenes are quite often described as (photo)-antimicrobial [32,33]. The fact that many fungal polyacetylenes are excreted into the broth is interesting: It fits to the hypothesis of Künzler, who claimed that antimicrobials are more likely to be excreted than to be stored intracellularly in hyphae [34]. However, antimicrobials could also be located on the hyphal wall (e.g., as incrusted pigments), thus protecting the hyphae from biological, physical, or chemical damage. Fungi produce antifungal compounds to ascertain their survival in their environment against other competing fungi.

A combined UV-light enhanced antimicrobial effect was already shown for polyacetylenes from plants several decades ago $[16,26]$. Since fungi produce analogs, the question arises if UV-light also enhances the antibacterial activity of fungal acetylenes [32, 35].

The biosynthetically closely related photoactive thiophenes are formed from polyacetylenes via the reaction with sulfur. Terthiophene (Fig. 2, 2) is highly photoactive [36-38]. Naturally, terthiophenes can be found in several plant species of the family Asteraceae, e.g., Tagetes erecta [39], Eclipta alba, or Bidens pilosa [40]. In contrast, thiophenes isolated from fungi are rare: The only one known is junipal (3) - a propynyl thiophene-which was isolated from the wood-decaying polyporoid fungus Daedalea juniperina [24].

\subsection{Alkaloids}

Beta-carboline alkaloids are, despite being neuroactive natural products [41], well-known photoactive natural products. After UV-A irradiation, their antitumor [42, 43], antimicrobial [44, 45], and anti-insecticidal [45] activities are enhanced. PDT type I [46] and PDT type II reactions 


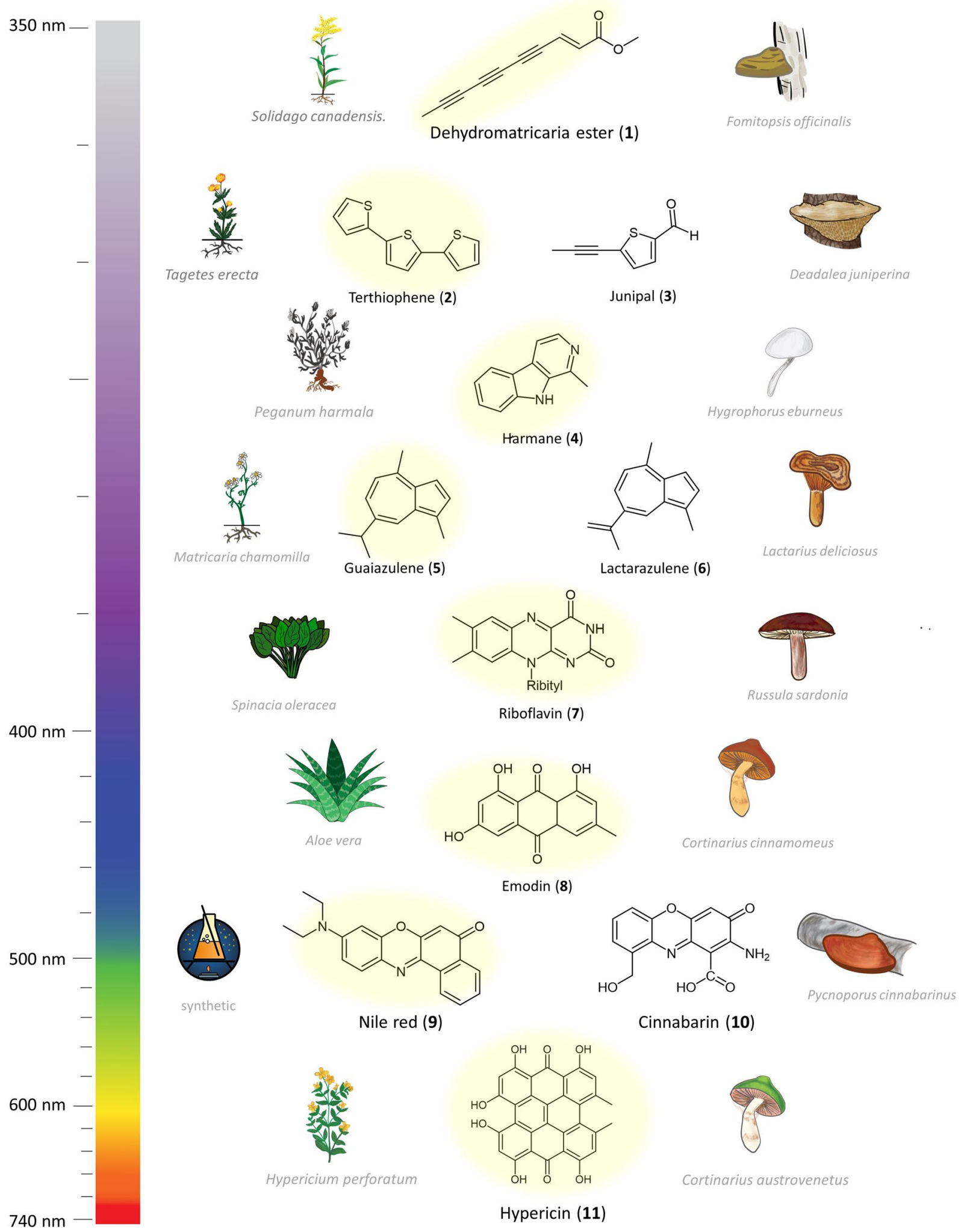

Fig. 2 Selected classes of natural photosensitizer isolated from plants (yellow) that are also found in fruiting bodies. Left: visualization of the plant from where this PS can be isolated. Right: Visualization of

the mushroom from where the PS (or a similar metabolite) can be isolated. Colorbar: Visualization of the excitation wavelength 

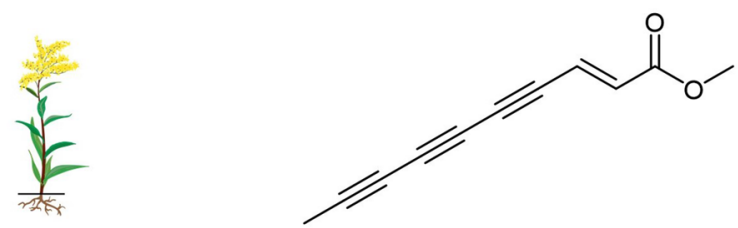

Solidago odora

\section{trans-Dehydromatricaria ester (1)}
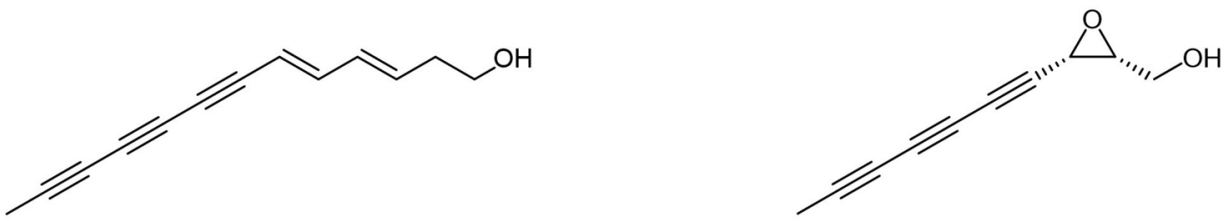

(3E,5E)-trideca-3,5-dien-7,9,11-triyn-1-ol (12) Leucanthemum adustum

Bioformin (16)

Trametes pubsescens

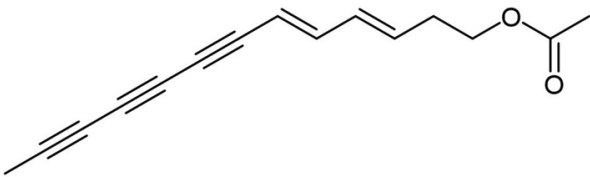<smiles>O=C(O)C#CC#CC(=O)O</smiles>

C8-Triynedioic acid (17)

Poria cocos

\section{acetate (13)}

Leuzea centauroides

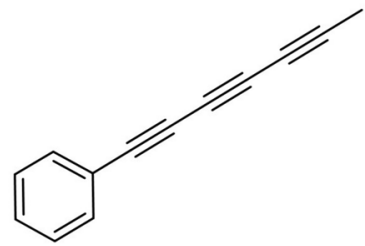

Phenylheptatriyne (14)

Biden pilosa
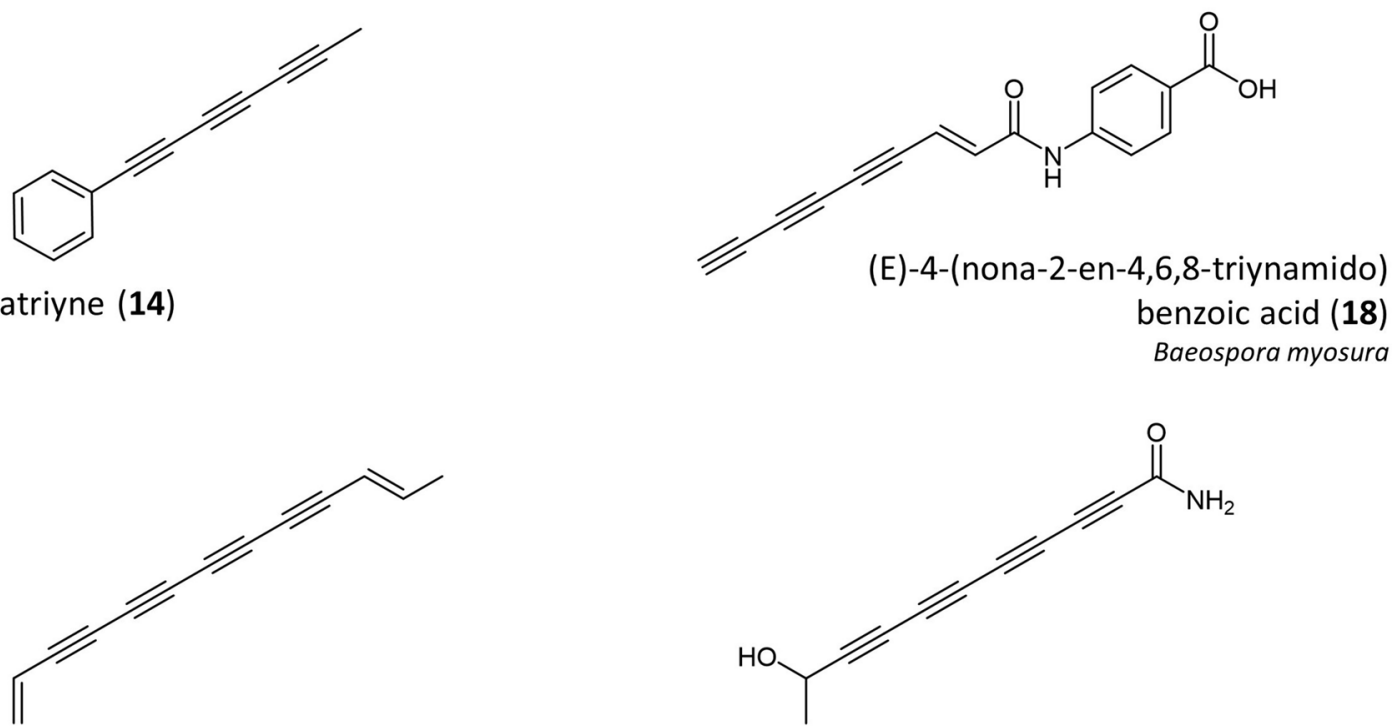

1,11-Tridecadiene-3,5,7,9-tetrayne (15) Biden hawaiensis.

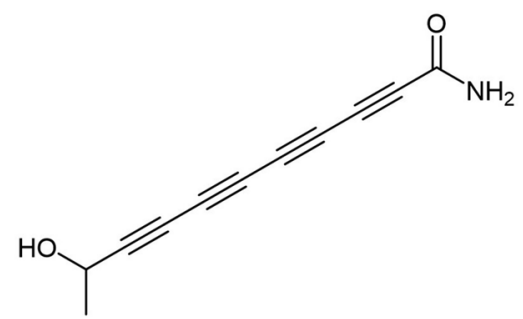

1-Hydroxyundeca-2,4,6,8-tetraynamide (19) Mycena viridimarginata

Fig. 3 Comparison of herbal and fungal polyacetylenes. All displayed polyenes from plants are known to be phototoxic. Fungal polyacetylenes were yet not photochemically studied 
were observed for beta-carboline like photosensitizers as well as DNA/RNA photooxidation [47]. Due to their chemical nature, the photochemistry of beta-carbolines such as norharmane (20), is pH-dependent. For example, their fluorescence properties: the protonated form of $\mathbf{2 0}$ is strongly fluorescent $\left(\phi_{\mathrm{F} \text {, air }}=0.7\right)$, while the deprotonated form emits rather weak fluorescence instead $\left(\phi_{\mathrm{F} \text {, air }}=0.2\right)$. The ability to produce singlet oxygen is, however, not as strongly affected (20, $\phi_{\Delta, \text { air, } \mathrm{pH}=5}=0.10$ vs. $\left.\phi_{\Delta, \text { air, } \mathrm{pH}=10}=0.08\right)$ [48].

Amongst others, the photoactive beta-carbolines harmane (4) and norharmane (20) were isolated from Hygrophorus eburneus [49]. They are, however, not limited to a single species of the genus Hygrophorus: LC-ESI-SRM analysis showed that these two beta-carbolines are present in 27 of 28 studied species [49]. Furthermore, harmane (4) and its methoxy analogous harmine (21) are widely distributed in the genus Psilocybe [50]. Beil and colleagues [50] reported that their content is independent of the developmental state of the fruiting bodies and that beta-carbolines were also found in the mycelium. For Psilocybe cubensis, they even reported a 100-fold higher harmane (4) content in the mycelium compared to the fruiting bodies, hinting towards a putative anti-nematocidal or antimicrobial function in these fungi. In addition, analogs like perlolyrine (22) substituted at position 1 were identified in Psilocybe [50]. Those betacarbolines were initially isolated from the caterpillar fungus Ophiocordyceps sinensis [51]. Another analog, flazin (23), was obtained from Suillus granulatus [52, 53] and Boletus umbriniporus [54]. Further derivatives are listed in a recent review [55], as for example infractin (24) and 6-hydroyinfractin (25) from Cortinarius curtisii [56] or the (hydrated) analogs isolated from Cortinarius brunneus (26-29). 4-Methylthiocanthin-6-on (30) was isolated from Boletus curtisii and 16 different harmane derivatives detected in
Mycena metata (not shown) [57]. Together with the isolated (hydro)-carbolines (not shown) from Hygrophorus hyacinthinus [49] and Amanita muscaria [58] this variety indicates that even more fungal species might produce such (pre)photosensitizers [59] and that a more diverse chemical space awaits discovery.

Exploring the photochemical potential of fungal alkaloids might provide more hints towards photo-defense mechanisms based on beta-carbolines. Although Cabrerizo and coworkers [60] suggest that beta-carbolines, in general, have a too low photoyield to be part of a defense strategy. Nevertheless, one observation hints towards a wound-induced mechanism: Teichert observed that the fluorescence (due to the beta-carbolines 26-28) increased where the fruiting body was impaired [61] (Fig. 4).

Pteride (31, Fig. 5) - a two cyclic heteroaromatic compound-represents the chemical backbone of several important biomolecules, e.g., folate and riboflavin (7). Folate, though being an essential vitamin, is photogenotoxic under UV-light irradiation $\left(360 \mathrm{~nm}, 3 \mathrm{~J} / \mathrm{cm}^{2}\right.$ ) [62]. In addition, riboflavin (7) and synthetic derivatives are photoactive, as shown by their ability to produce singlet oxygen under irradiation [63]. Nevertheless, photoprotective properties were also demonstrated for riboflavin [64], thus riboflavin's phototoxicity seems strongly concentration and irradiation dependent. Riboflavin (7) can be isolated from several higher fungi [65], as for example from Calocybe chrysenteron [66] or Russula xerampelina ( $\eta=12.6 \%$ DW) [67]. The product of the photoinduced degradation or the metabolism of $\mathbf{7}$ is lumichrom (32) which was identified in Cortinarius brunneus [61]. In the regnum Fungi, other pteride-like structures were isolated from several Russula species and consequently named russupteridines [67], some of them are representatively shown in Fig. 5 (33 and $\mathbf{3 4}$ ). The yields

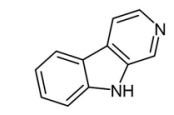

Norharmane (20) Hygrophorus eburneus

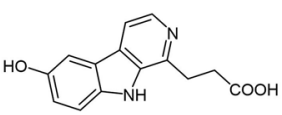

6-Hydroxyinfractin (25) Cortinarius infractus

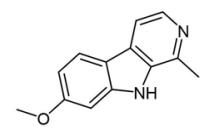

Harmine (21) Hygrophorus eburneus

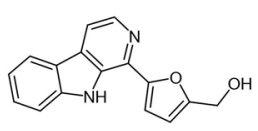

Perlolyrine (22) Psilocybe cubensis

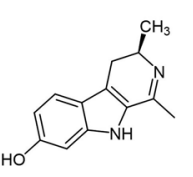

Brunnein A (28) Cortinarius brunneus

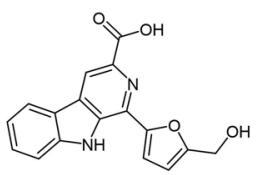

Flazin (23) Boletus umbriniporus

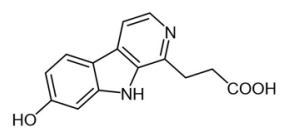

3-(7-Hydroxy-9H-ß-carbolinyl) -propionsäure (29) Cortinarius brunneus

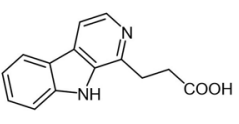

Infractin (24)
Cortinarius infract

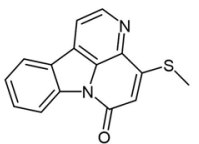

4-Methylthiocanthin-6-on (30) Boletus curtisii

Fig. 4 The different beta-carbolines isolated i.a. from the indicated fungi. $\mathbf{2 0}$ and $\mathbf{2 1}$ are known as photoactive compounds from herbs. None of the fungal beta-carbolines was studied in this respect yet 
Fig. 5 Photoactive pteride and anologues. $\mathbf{3 1}$ and $\mathbf{3 5}$ are widely distributed photoactive secondary metabolites, while the others are specific fungal pigments

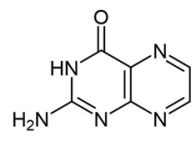

Pteridine (31)

$\Phi_{\Delta}=0.3(\mathrm{pD}=10.5)$

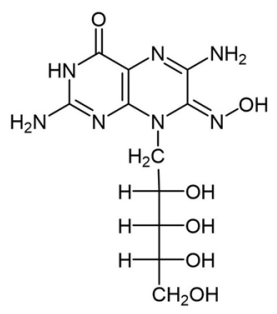

Russupteridineyellow I (34) Russula paludosa<smiles>Cc1cc2nc3[nH]c(=O)n(C)c(=O)c3nc2cc1C</smiles>

Lumichrom (32) Cortinarius brunneus<smiles>CC(O)C(O)C(O)COC1OC(CO)[C@@H](O)[C@H]1O</smiles>

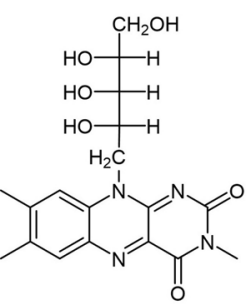
3N-Methyl riboflavin (35)
Panellus serotinus

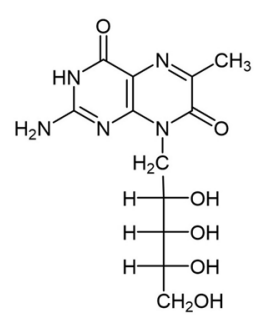

Russupteridine (33) Russula emetica

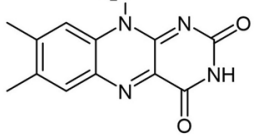

Lampteroflavin (36) Omphalotus japonicus are, however, quite low; Iten and colleagues needed $200 \mathrm{~kg}$ of fresh Russula sardonia to isolate $110 \mathrm{mg}(\eta=0.000055 \%)$ of $\mathbf{3 4}$ [67]. Compounds 32-34 are responsible for the strong fluorescence of the fruiting bodies $[65,68]$ and thus ought to be photochemically investigated. Other analogues of $\mathbf{3 2}$ which hint towards a potential photoactive precursor analog to 7-are $3 \mathrm{~N}$-methyl riboflavin (35) from the late oyster (Panellus serotinus) or lampteroflavin (36) from the bioluminescent tsukiyotake (Omphalotus japonicus).

Berberine-like photosensitizers, such as berberine (Fig. 6, 37) [69] or sanguinarine [70] are isoquinoline alkaloids. From endophytic Ascomycota, it is known that they may produce berberine (37) [71]. In Basidiomycota, however, only isoquinoline-like alkaloids were found. In detail, the pale ochraceous Cortinarius subtortus contains 6-hydroxyquinoline-8-carboxylic acid (38) and 4-amino-6-hydroxyquinoline-8-carboxylic acid (39), as well as 7-hydroxy1-oxo-1,2-dihydroisoquinoline-5-carboxylic acid (40) [72]. If $\mathbf{3 8} \mathbf{- 4 0}$ are indeed photoactive, might be questionable, as the chemical similarity is limited.
Phenoxazines are $\mathrm{N}-\mathrm{O}$ heterocycles with a stunning similarity to the synthetic PSs Nile blue and Nile red (Fig. 7, 9) [70, 73]. In its oxidized form-as the phenoxazones cinnabarin (41), tramesanguin (42), and cinnabarinic acid (43) - this structural class was shown to be the coloring principle of the red-orange wood-decaying polypores Pycnoporus sanguineus, $P$. cinnabarinus, and P. coccineus [74-77]. Furthermore, the phenoxazon 2-aminophenoxazin-3-one (44) occurs wound-induced in the agaricoid Lepiota americana (synonymous Leucoagaricus americanus) [78]. After softly brushing the white flesh, it turns first yellowish and, after a while, red. No other Lepiota species was chemically investigated in an analogous manner. Yet, it is known from classical mycological descriptions that several Lepiota and related Macrolepiota turn red after impairment of the agaricoid fruiting body [79]. Nearly 45 years ago, another related observation was reported by Kuchen and Schlunegger [80]: they observed that the culture medium of Calocybe gambosa turns reddish after approx. 1 month of cultivation. Subsequent
Fig. 6 Isoquinoline alkaloids from plants (37) and isolated from Basidiomycota<smiles>COc1ccc2cc3[n+](cc2c1OC)CCc1cc2c(cc1-3)OCO2</smiles>

Berberine (37)<smiles>[R]c1ccnc2c(C(=O)O)cc(O)cc12</smiles>

$\mathrm{R}=\mathrm{H}$ (38)

$\mathrm{R}=\mathrm{NH}_{2}$ (39)<smiles>O=C(O)c1cc(O)cc2c(=O)[nH]ccc12</smiles>

40 
<smiles>CCN(CC)c1ccc2nc3c4ccccc4c(=O)cc-3oc2c1</smiles>

Nile red (9)<smiles>[R]Cc1cccc2oc3cc(=O)c(N)c(C(=O)O)c-3nc12</smiles>

$\mathrm{R}=\mathrm{OH}$, Cinnabarin (41)

$\mathrm{R}=\mathrm{CHO}$, Tramesanguin (42)

$\mathrm{R}=\mathrm{COOH}$, Cinnabarinic acid (43) Pycnoporus sanguineus<smiles>[R]c1cc2nc3ccccc3oc-2cc1=O</smiles>

$\mathrm{R}=\mathrm{NH}_{2}$, 2-Aminophenoxazin -3-one (44)

Leucoagaricus americana

$\mathrm{R}=\mathrm{H}$, Phenoxazon (45)

Calocybe gambosa

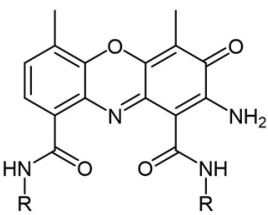

Actinomycin D (46)

$\mathrm{R}=$ cyclic hexapeptide

Fig. 7 Phenoxazines with the synthetic compound $\mathbf{9}$ and the FDA approved chemotherapeutica (46) in comparison to several analogous structures isolated from fruiting bodies (41-45)

analysis revealed the accumulation of the phenoxazones 44 and 45. Photochemical studies were not done yet with these fungal pigments. Their interesting dark bioactivities hint towards antitumor [81] and antimicrobial [82] activities, which might be enhanced by irradiation. Although, the structurally related actinomycin D (46) showed no phototoxicity against poliovirus in an old study (1966) [83], interesting photobiological or photochemical properties of 41-45 cannot be denied.

Azobenzenes are to some extent distributed in macromyceta [84]. For example, 4,4'-dihydroxyazobenzene was identified as the yellow stain of the toxic button mushroom (Agaricus xanthoderma). While the mushroom is normally white, its flesh rapidly takes on a yellow stain after being damaged [85]. Small molecules containing an azobenzene function are used in optogenetics and as photoswitches of membrane proteins $[86,87]$.

\subsection{Phenalenone}

Phenalenone (Fig. 8, 47) is a universal reference compound for singlet oxygen production, as its photoyields reach unity (i.e., $\phi_{\Delta}=1$ ) in a wide variety of solvents [88]. Though not yet described from fruiting bodies forming Basidiomycota, hydroxylated phenalenones and analogous compounds are widely spread in Ascomycota [89]. For example, funalenone 48 was obtained from Aspergillus niger [90], and new derivatives are frequently isolated from marine sponges [91, 92]. Mono-hydroxylated phenalenones-as for example the 3-hydroxy phenalenone 49-differ in their photochemical properties as compared to $\mathbf{4 7}$, however, they continue to be interesting PSs [93, 94]. Next to the known phototoxic phenyl-phenalenones (50), Flors and Nonell [5] reviewed related photoactive alkaloids from plants, namely oxoaporphines, oxoisoaporphines, and azaporohines. Oxoglaucine (51) is of
Fig. 8 Photoactive phenalenones and phenalenone-like structures from plants $(\mathbf{5 0}, \mathbf{5 1})$ and from ascomycetes $(\mathbf{4 8}, \mathbf{4 9})$ as well as basidiomycetes (52)<smiles>O=C1C=Cc2cccc3cccc1c23</smiles><smiles></smiles>

9-Phenylphenalenon (50) Banana (Musa fijiensis)<smiles>COC1=C(O)c2c(O)cc(C)c3c(O)cc(O)c(c23)C1=O</smiles>

Funalenone (48) Aspergillus niger<smiles>COc1cc2c(cc1OC)-c1c(OC)c(OC)cc3ccnc(c13)C2=O</smiles>

Oxoglaucine (51) Xylopia aethiopica<smiles>O=C1C=C(O)c2cccc3cccc1c23</smiles>

3-Hydroxyphenalenone (49)<smiles></smiles>

Necatrone (52) Lactarius necator 
special interest, as it reaches photoyields in apolar solvents between $\phi_{\Delta}=0.5$ (acrylonitrile) and $\phi_{\Delta}=1$ (toluene). Only the faintly related alkaloide necatrone $\mathbf{5 2}$ is described from Basidiomycota, in more detail from Lactarius spp. [95]. Nevertheless, with the continuous progression of modern phytochemical techniques [96], it is possible that analogue polyketide phenalenones will be detected in macromycota.

\subsection{Sesquiterpene lactones-azulene}

In 1935, Willstaed [97] described the coloring matter of Lactarius deliciosus as azulene and named it lactarazulene (6) (Fig. 9). This fungal pigment is exceptionally similar to guaiazulene (5), a phototoxic compound that produces superoxide after irradiation [98]. Photophysical or photobiological studies of 6 were not conducted yet, even though Halbwachs and colleagues [99] pointed this coincidence out already. Guaiane sesquiterpenes are chemotaxonomic markers of the Lactarius section Dapetes, to which the edible saffron milk cap (Lactarius deliciosus) and L. salmonicolor belong [100]. By comparing frozen young fruiting bodies with older damaged ones, Bergendorff and Sterner discovered that fatty acid bound derivatives of a reduced azulene derivative (e.g., 53) are genuinely present in young mushrooms [101]. Nevertheless, as soon as the fruiting body is damaged, a reddish latex pours out, and with it the free alcohol (54) and highly conjugated derivatives like lactaroviolin (55). Many of these compounds seemed to be light sensitive and relatively unstable, which necessitates an advanced isolation protocol [101]. The wound-induced mechanism is a hint towards the role as a defense molecule. Whether a photochemical process is involved or not was not tested yet.

\subsection{Anthraquinones and perylene quinones}

As the largest group of natural pigments with a quinoid structure, anthraquinones (AQs, Fig. 10) are widely spread in nature; they were discovered in the phyla bacteria, fungi, lichens, plants [102], and even insects [103]. More than 80 AQs were already described from Basidiomycota at the beginning of the 90th of the last century [104]. Since then, several more were discovered, especially from toadstools native to the Southern Hemisphere (Australia and New Zealand) [105].

Numerous AQs are well-known photosensitizers: Emodin (8), physcion (58), and aloe-Emodin (59), just to name a few examples [4]. $\mathbf{8 , 5 8}$, and $\mathbf{5 9}$ produce singlet oxygen, and thus PDT type II-like activities were proposed [106, 107] in combination with PDT type I reactivities [108]. In addition to their wide-spread occurrence in the kingdom Plantae, 8 [109] and $\mathbf{5 8}$ [109] are chemotaxonomic markers [110] for mushrooms. In detail, these and other AQs are markers for the ectomycorrhizal genus Cortinarius subgenus Dermocybe, which is characterized by brightly colored fruiting bodies.

Just recently, we started to explore this coincidence [111] and were thereby able to show a common photoactivity scheme in this subgenus. Furthermore, we were also able to isolate and to describe new AQ-like PSs from Cortinarius i.a. the dimeric AQ 7,7'-Biphyscion (60) which under irradiation exhibits antitumor activities in the nanomolar range
Fig. 9 The photoactive azulene 5 with its relative fungal metabolites $\mathbf{6}$ an 53-55, all isolated from Lactarius deliciosus<smiles>CC1=CC2C(=O)c3cc(O)cc(O)c3C(=O)C2C(O)=C1</smiles>

Emodin (8)

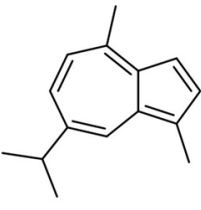

Guaiazulene (5) Bulnesia sarmientoi

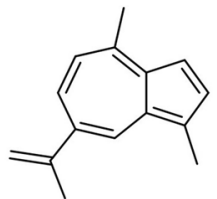

Lactarazulene (6) Lactarius deliciosus

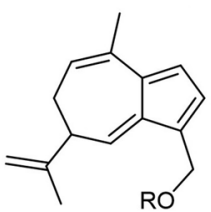

$\mathrm{R}=\mathrm{CO}\left(\mathrm{CH}_{2}\right)_{15} \mathrm{CH}_{3}$ $\mathrm{R}=\mathrm{H}(\mathbf{5 4})$

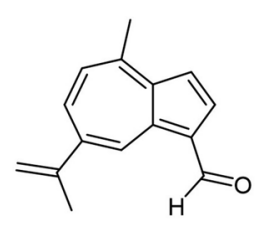

Lactaroviolin (55) Lactarius deliciosus
(53)

Fig. 10 Photoactive monomeric anthraquinones as well as the fungal dimeric AQ (-)-7,7'-biphyscion (60), which is photoactive 
[112]. Another chemotaxonomic marker of the Cortinarius subgenus Dermocybe is hypericin (11), underlining further the hypothesis of a general phototoxicity in dermocyboid Cortinarii. Next to the AQs and perylene quinones several other metabolites of the polyketide pathway display highly conjugated aromatic systems [65] with potential promising photochemical properties. Thus, the widely distributed AQs are one of the strongest and most definite hints pointing towards a photochemical defense mechanism in Basidiomycota. As fungi produce unique AQs, their potential photoactivity is a yet unexplored source for structurally new PSs for anticancer and/or antimicrobial applications.

\section{What we know from phototoxic plants and what we might extrapolate to mushrooms}

Fungi and plants are genetically distinct, yet both produce immobile life forms and thus lack the ability to escape from predators. Consequently, a versatile chemical defense battery evolved $[11,14]$. One of many is the photoactivated defense, as proven for the kingdom Plantae [7]. According to the optimal defense hypothesis, plants synthesize cost-intensive defense molecules in a regulated manner [113] to selectively protect only the most precious parts. While comparing plants and basidiomycetes, we need to keep in mind that a fungal fruiting body is nothing more than a lemon for a lemon tree.

In general, fruits are crucial for the survival of a species, and they are known to accumulate PSs. For example, furanocoumarins are highly concentrated in the oil and pulp of several citrus species (e.g., lemon, lime, pomelo) [114, 115]. Earlier developmental stages of fruits, e.g., the inflorescences, are also known to contain high levels of PSs. Photoactive polyacetylenes of Clibadium surinamense are, for example, enriched in the inflorescence [116]. Furthermore, in seeds, a significant number of PSs were detected, as for example harmine (21) in Peganum harmala [117]. From plants we know that compared to other tissues, the reproducing tissues are especially well protected due to a higher concentration of PSs. Therefore, it is per se not unlikely that fungi also produce PSs as defense mechanisms for their reproductive structures, i.e., for their fruiting bodies.

In sunny states such as California, the "lime" dermatitis is widely distributed [118-120] and caused by furanocoumarins in lemons [114]. Sun protection is commonly used as a precaution and as treatment. However, not only the herbivore-consuming PSs needs protection. The organism producing PSs needs certain protection mechanism as well, to not become a victim of its own bullets. One of such is the accumulation of PSs in tissues hidden from the sun. Phenylphenalenone (50), for example, is stored in the roots of Lachnanthes tinctoria [121]. In comparison with fungi, this would imply that the fungus accumulates PSs in its underground hyphal structures. Reports about the distribution of fungal pigments in the mycelium of basidiomycetes are rare. From the dermocyboid Cortinarii, we know that AQs are also found in the mycelium, but solely the acidic ones were detected [122]. From Psilocybe cubensis, we know that the PS harmane (4) is 100fold higher concentrated in the mycelium compared to the fruiting body [50].

Another known strategy of the regnum Plantae against the toxic sunlight is the concentration of PSs in special glands (e.g., hypericin in dark glands of Hypericum perforatum [123]) or resin canals (e.g., thiarubins in resin canals of the outer cortex of Ambrosia [124-126] or in the roots of Chaenactis douglasii [127]). Representatives of the regnum Fungi are-in this regard-not as intensively studied. Old studies suggest that Cortinarii store pigments in vacuoles [128, 129]. In different Lactarius spp., the wide variety of azulene-like pigments is not genuinely present in the fruiting bodies but occurs after impairment together with the characteristic latex [101]. The latter is another way of protection, i.e., the intrahyphal storage of precursors lacking the actual toxicity. In the kingdom Plantae, this is, e.g., known from Magnoliaceae where the non-phototoxic glaucine is predominantly found in healthy tissue. In contrast, the phototoxic oxoglaucine (51) is present as the main product after mechanical injury [5]. Taken together, while it might be contra intuitive that plants growing in the sun produce potentially auto-toxic PSs as defense molecules [130], manifold mechanism evolved to protect the PS producing plant from self-induced burning.

However, does a mushroom need light protection in the shady forest at all? A generic number regarding the distribution of light in forests is not easy to give, as it strongly depends on the type of trees forming the canopy and on the season [131-134]. Nevertheless, as a rule of thumb, it is assumed that in a boreal pine forest (Pinus sylvestris) approx. 34\% of the incoming radiation (300-3000 nm) reaches the ground [135] and through spruce (Picea sitchensis) $17-26 \%$ of the visible sunlight $(480-600 \mathrm{~nm})$ [136]. Hofmeister [137] mentioned that in extreme cases, only $5 \%$ of the incoming light reaches the ground vegetation. In addition, agaricoid Basidiomycota are characterized by an umbrella-shaped fruiting body. Thus, it can be claimed that many toadstools are equipped with inherent sun protection in an already quite shady surrounding. Consequently, the cap is somewhat exposed to the sun, while the precious lamellas, carrying the spores, are protected from the sun. According to the optimal defense hypothesis [113], fungi would protect only the most precious parts of the fruiting body, i.e., the gills carrying the spores. Thus, the specific pileus-shape and the ecological niche might already count as self-protection against the potential harmful sunrays. 


\section{Outlook-ideas and thoughts for future experiments}

As demonstrated above, photosensitizers are not only metabolites of the kingdom Plantae but also of the kingdom Fungi, or more specifically, of the phyla Basidiomycota. While some ascomycetes synthesizing photosensitizer are known [138-143], the field of PS-generating mushrooms is in its infancy.

To explore this new field, the pigment classes of fungi should be systematically studied to verify the expected and to validate the assumed. Screening protocols exist [111, 144], though adjustments are needed, as one part of a current method depends on an anthracene-like compound (i.e., dimethyl anthracene (DMA)) as the singlet oxygen scavenger. In consequence, this assay works well for pigments absorbing wavelength above $450 \mathrm{~nm}$, but it is not suited for the UV-A range or high energetic blue light, as the probe itself absorbs light in this range. Nevertheless, the assay's logic can be easily adapted to a UV-A/blue light compatible probe such as 1,4-dimethylnaphthalene (DMN) or 2-pyridone [145].

Next to a photochemical assay, screening workflows should always include in vitro assays to verify the biological effect and thus the pharmacological relevance. Due to the PS's Janus-like selectivity (i.e., light-dependent selectivity and mechanism-dependent unselectivity), endless pharmaceutical and disinfection applications can be thought of. Classic targets of PSs are antitumor, antimicrobial, anti-insecticidal, or anti-viral. Thus, it is a promising field which-in theory-should be intrinsically exhilarated. Nevertheless, the number of newly identified natural PSs lags behind rational expectations. This lack-as well as the lacking systematic structure-activity studies producing semi-synthetic analogs, as known from classical medicinal chemistry approaches-is due to the absence of broadly established HTS approaches. However, the continuous progress in the LED-techniques and thus LED-arrays, will hopefully resolve this issue.

During natural PS screenings, one needs to keep in mind that the PSs might not be genuinely present but might be wound-induced formed from Pre-PSs. In Nature, most likely oxygen, light, or enzymes will catalyze this transformation. Thus, drying fresh grounded mushroom material under hot-air and/or leaving extracted samples longer exposed to air potentially increases the observed photo-activity. While this point is less relevant-or even beneficial-from a medicinal chemistry point of view, it is essential while tackling questions belonging to the field of the chemical ecology.

To study the genuine form of natural PSs several wellestablished processes might be considered. For example, localization studies as known from phytoalexin studies [146], including HR-MALDI-MS [57] or Raman-imaging [147] processes, might be utilized or-if possible-cocultivation experiments done to selectively trigger the synthesis of defense molecules [148]. Furthermore, it would be of interest to explore the distribution of photoactive compounds (or their precursors) in the fungal tissue. Is there a significant concentration difference in the mycelium $v s$ the fruiting bodies? Or across the fruiting body? Are gills for example enriched in PSs as compared to the pileus? Is there a correlation between the existence of PSs in plants and the ectomycorrhizal forming fungi? Did such photoactivities evolve together in plants and fungi?

From Eisfelder's $[149,150]$ impressive work 60 years ago, we know that fungi can be distinguished in "käferreich" and "käferfremd", meaning those on which a lot of larvae are found and those where insects are rarely found. Interestingly, especially some of the very colorful mushrooms belong to the species ignored by insects. It should be clarified if this empirically observed activity, which was experimentally verified by Besl and Blumreisinger [151], is modified by light. Though using fungi larvae might be the obvious starting point, a control organism (like Caenorhabditis elegans) should be included as well, to exclude evolutionary learned effects. Other than for secondary metabolites in general, the concentration of the PS in the fungal tissues should primarily not depend on external factors such as weather conditions. Rather, an attack by fungivores or other microbials should induce their production. While this is "easy" to study with all saprophytic fungi, which can be cultivated under controlled conditions, with ectomycorrhizal fungi, it is more challenging and thus needs creative approaches.

\section{Conclusion}

In this perspective, the similarity was elaborated between plant-based PSs and pigments of fungal fruiting bodies. A coincidental existence of the vast number of PSs and PS analogous structures in fungi appears questionable, especially as many parallels between plant-based PSs and fungal pigments can be identified. This turns the search for PSs in the fungal world into a fascinating leeway. While only future research can show if photochemical defense strategies are indeed an ecological function of fungal pigments, it is already obvious that studying the photochemistry and photobiology of fungal pigments is an exciting field with promising output for structurally new PSs.

Acknowledgements Prof. U. Peintner, Dr. P. Vrabl, and Prof. H. Stuppner are thanked for their critical reading and valuable input. Dr. N. Engels English proof reading is highly appreciated. The support of this work by the Tyrolean Science Fund is kindly acknowledged. 
Funding Open access funding provided by University of Innsbruck and Medical University of Innsbruck.

\section{Declarations}

Conflict of interest There are no conflicts to declare.

Open Access This article is licensed under a Creative Commons Attribution 4.0 International License, which permits use, sharing, adaptation, distribution and reproduction in any medium or format, as long as you give appropriate credit to the original author(s) and the source, provide a link to the Creative Commons licence, and indicate if changes were made. The images or other third party material in this article are included in the article's Creative Commons licence, unless indicated otherwise in a credit line to the material. If material is not included in the article's Creative Commons licence and your intended use is not permitted by statutory regulation or exceeds the permitted use, you will need to obtain permission directly from the copyright holder. To view a copy of this licence, visit http://creativecommons.org/licenses/by/4.0/.

\section{References}

1. Gill, M., Gimenez, A., \& McKenzie, R. W. (1988). Pigments of fungi, part 8. Bianthraquinones from Dermocybe austroveneta. Journal of Natural Products, 51(6), 1251-1256.

2. Gill, M., \& Giménez, A. (1991). Austrovenetin, the principal pigment of the toadstool Dermocybe austroveneta. Phytochemistry, 30(3), 951-955.

3. Towers, G. H. N. (1986). Significance of phototoxic phytochemicals in insect herbivory. Journal of Chemical Ecology, 12(4), 813-821.

4. Siewert, B., \& Stuppner, H. (2019). The photoactivity of natural products - an overlooked potential of phytomedicines? Phytomedicine, 60, 152985.

5. Flors, C., \& Nonell, S. (2006). Light and singlet oxygen in plant defense against pathogens: phototoxic phenalenone phytoalexins. Accounts of Chemical Research, 39(5), 293-300.

6. Downum, K. R. (1992). Light-activated plant defence. New Phytologist, 122(3), 401-420.

7. Berenbaum, M. (1995). Phototoxicity of plant secondary metabolites: Insect and mammalian perspectives. Archives of Insect Biochemistry and Physiology, 29(2), 119-134.

8. Hölscher, D., et al. (2014). Phenalenone-type phytoalexins mediate resistance of banana plants Musa spp. to the burrowing nematode Radopholus similis. Proceedings of the National Academy of Sciences, 111(1), 105-110.

9. Samuels, R., \& Knox, P. (1989). Insecticidal activity of hypericin towards Manduca sexta larvae. Journal of Chemical Ecology, 15(3), 855-862.

10. Song, R., et al. (2017). Phytoalexin phenalenone derivatives inactivate mosquito larvae and root-knot nematode as type-ii. Photosensitizer., 7, 42058.

11. Spiteller, P. (2008). Chemical defence strategies of higher fungi. Chemistry, 14(30), 9100-9110.

12. Hellwig, V., et al. (2002). Calopins and cyclocalopins-bitter principles from Boletus calopus and related mushrooms. European Journal of Organic Chemistry, 2002(17), 2895-2904.

13. Spiteller, P. (2015). Chemical ecology of fungi. Natural Product Reports, 32(7), 971-993.

14. Spiteller, D. (2008). Plant Defense Strategies. In S. E. Jørgensen \& B. D. Fath (Eds.), Encyclopedia of ecology (pp. 2798-2811). Oxford: Academic Press.
15. Hudson, J. B., \& Towers, G. H. (1991). Therapeutic potential of plant photosensitizers. Pharmacology and Therapeutics, 49(3), 181-222.

16. Marchant, Y. Y., \& Cooper, G. K. (1987). Structure and function relationships in polyacetylene photoactivity. Light-sctivated pesticides (pp. 241-254). American Chemical Society.

17. Negri, R. (2015). Polyacetylenes from terrestrial plants and fungi: recent phytochemical and biological advances. Fitoterapia, 106, 92-109.

18. Anchel, M. (1952). Acetylenic compounds from fungi. Journal of the American Chemical Society, 74(6), 1588-1590.

19. Bu'Lock, J. D. (1966). 5-Biosynthesis of polyacetylenes in fungi. In J. F. Snell (Ed.), Biosynthesis of antibiotics (pp. 141157). London: Academic Press.

20. Thongbai, B., et al. (2017). Successful cultivation of a valuable wild strain of Lepista sordida from Thailand. Mycological Progress, 16(4), 311-323.

21. Anchel, M. (1955). Structure of diatretyne 2, an antibiotic polyacetylenic nitrile from Clitocybe diatreta. Science, 121(3147), 607-608.

22. Palma, N., \& Knauseder, F. (1980). PA 789/80, a polyacetylenic antibiotic from Marasmius alliaceus (Jacq. Ex. Fr.) Fr. The Journal of Antibiotics, 33(12), 1556-1559.

23. Bohlmann, F., et al. (1980). Sesquiterpene and diterpene derivatives from Solidago species. Phytochemistry, 19(12), 2655-2661.

24. Birkinshaw, J. H., \& Chaplen, P. (1955). Biochemistry of the wood-rotting fungi. 8. Volatile metabolic products of Daedalea juniperina Murr*. Biochemical Journal, 60(2), 255-261.

25. Schulte, K. E., Rücker, G., \& Fachmann, H. (1969). Polyacetylene als Inhaltsstoffe des Lärchenschwammes (Fungus Laricis). Archiv der Pharmazie, 302(12), 965-973.

26. Towers, G. N. H., et al. (1979). Phototoxic polyacetylenes and their thiophene derivatives [effects on human skin]. Contact Dermatitis, 5(3), 140-144.

27. Li, G.-H., Shen, Y., \& Zhang, K. (2005). Nematicidal activity and chemical component of Poria cocos. The Journal of Microbiology, 43, 17-20.

28. Dagne, E., Asmellash, S., \& Abate, D. (1994). An antifungal polyacetylenic compound from the culture filtrate of the fungus Trametes pubescens. Journal of Natural Products, 57(3), 390-392.

29. Parish, C. A., et al. (2004). A new ene-triyne antibiotic from the fungus Baeospora myosura. Journal of Natural Products, 67(11), 1900-1902.

30. Jente, R., et al. (1985). Tetra-acetylenic metabolites from Mycena viridimarginata. Phytochemistry, 24(3), 553-559.

31. Yoke Marchant, Y., \& Neil Towers, G. H. (1987). Phylloplane fungi of Hawaiian plants and their photosensitivity to polyacetylenes from Bidens species. Biochemical Systematics and Ecology, 15(1), 9-14.

32. Minto, R. E., \& Blacklock, B. J. (2008). Biosynthesis and function of polyacetylenes and allied natural products. Progress in Lipid Research, 47(4), 233-306.

33. Kuklev, D. V., Domb, A. J., \& Dembitsky, V. M. (2013). Bioactive acetylenic metabolites. Phytomedicine, 20(13), 1145-1159.

34. Künzler, M. (2018). How fungi defend themselves against microbial competitors and animal predators. PLOS Pathogens, 14(9), e1007184.

35. Chobot, V., et al. (2006). Phototoxic activity of a thiophene polyacetylene from Leuzea carthamoides. Fitoterapia, 77(3), 194-198.

36. Luan, S., et al. (2018). Photosensitization of Chinese hamster V79 cells to photoactivated alpha-terthienyl involving membrane damage and oxidative stress. Journal of Photochemistry and Photobiology B: Biology, 185, 192-198. 
37. Hudson, J. B., et al. (1993). The anti-HIV activities of photoactive terthiophenes. Photochemistry and Photobiology, 58(2), 246-250.

38. Hudson, J. B., et al. (1986). Antiviral activity of the photoactive thiophene $\alpha$-terthienyl. Photochemistry and Photobiology, 44(4), 477-482.

39. Zehmeister, L., \& Sease, J. (1947). A blue-fluorescing compound, terthienyl, isolated from marigold. J Amer Chem Soc, 69, 273.

40. Wat, C.-K., Johns, T., \& Towers, G. H. N. (1980). Phototoxic and antibiotic activities of plants of the asteraceae used in folk medicine. Journal of Ethnopharmacology, 2(3), 279-290.

41. Piechowska, P., Zawirska-Wojtasiak, R., \& Mildner-Szkudlarz, S. (2019). Bioactive $\beta$-Carbolines in Food: A Review. Nutrients, 11(4), 814.

42. McKenna, D. J., \& Towers, G. H. N. (1981). Ultra-violet mediated cytotoxic activity of $\beta$-carboline alkaloids. Phytochemistry, 20(5), 1001-1004.

43. Towers, G. H. N., \& Abramowski, Z. (1983). UV-mediated genotoxicity of furanoquinoline and of certain tryptophan-derived alkaloids. Journal of Natural Products, 46(4), 572-577.

44. Olmedo, G. M., et al. (2017). UVA photoactivation of harmol enhances its antifungal activity against the phytopathogens penicillium digitatum and Botrytis cinerea. Frontiers in Microbiology, 8, 347.

45. Larson, R. A., et al. (1988). $\beta$-carboline alkaloids: mechanisms of phototoxicity to bacteria and insects. Photochemistry and Photobiology, 48(5), 665-674.

46. Gonzalez, M. M., et al. (2012). Photosensitized electron transfer within a self-assembled norharmane-2'-deoxyadenosine 5'-monophosphate (dAMP) complex. Organic and Biomolecular Chemistry, 10(47), 9359-9372.

47. Denofrio, M. P., et al. (2020). N-Methyl- $\beta$-carboline alkaloids: structure-dependent photosensitizing properties and localization in subcellular domains. Organic and Biomolecular Chemistry, 18(33), 6519-6530.

48. Gonzalez, M. M., et al. (2009). One- and two-photon excitation of $\beta$-carbolines in aqueous solution: ph-dependent spectroscopy, photochemistry, and photophysics. The Journal of Physical Chemistry A, 113(24), 6648-6656.

49. Teichert, A., et al. (2008). Determination of $\beta$-carboline alkaloids in fruiting bodies of Hygrophorus spp. by liquid chromatography/electrospray ionisation tandem mass spectrometry. Phytochemical Analysis, 19(4), 335-341.

50. Blei, F., et al. (2020). Simultaneous production of psilocybin and a cocktail of $\beta$-carboline monoamine oxidase inhibitors in "magic" mushrooms. Chemistry, 26(3), 729-734.

51. Yang, M.-L., et al. (2011). Anti-inflammatory principles from Cordyceps sinensis. Journal of Natural Products, 74(9), 1996-2000.

52. Jiang, M.-Y., Feng, T., \& Liu, J.-K. (2011). N-containing compounds of macromycetes. Natural Product Reports, 28(4), 783-808.

53. Dong, Z., et al. (2007). Chemical constituents of the fruiting bodies from the basidiomycete Suillus granulatus. Chin Tradit Herb Drugs, 38, 17-19.

54. Lee, Y.-J., et al. (2015). an indole alkaloid from the fruiting body of Boletus umbriniporus. The Korean Journal of Mycology, 43, 68-70.

55. Homer, J. A., \& Sperry, J. (2017). Mushroom-derived indole alkaloids. Journal of Natural Products, 80(7), 2178-2187.

56. Steglich, W., et al. (1984). Indolalkaloide aus dem Blätterpilz Cortinarius infractus (Agaricales). Tetrahedron Letters, 25(22), 2341-2344.
57. Jaeger, R. J. R., et al. (2013). HR-MALDI-MS imaging assisted screening of $\beta$-carboline alkaloids discovered from Mycena metata. Journal of Natural Products, 76(2), 127-134.

58. Matsumoto, T., et al. (1969). Isolierung von (-)-R-4-Hydroxypyrrolidon-(2) und einigen weiteren Verbindungen aus Amanita muscaria. 31. Mitteilung über Inhaltsstoffe von Fliegenpilzen. Helvetica Chimica Acta, 52(3), 716-720.

59. Villarruel, F., et al. (2019). Light-induced full aromatization and hydroxylation of 7-methoxy-1-methyl-3,4-dihydro$2 \mathrm{H}$-pyrido[3,4-b]indole alkaloid: oxygen partial pressure as a key modulator of the photoproducts distribution. Journal of Photochemistry and Photobiology B: Biology, 199, 111600.

60. Rasse-Suriani, F. A. O., et al. (2018). Photophysical and photochemical properties of naturally occurring normelinonine $\mathrm{F}$ and melinonine $\mathrm{F}$ alkaloids and structurally related $\mathrm{N}(2)$ - and/ or N(9)-methyl- $\beta$-carboline derivatives. Photochemistry and Photobiology, 94(1), 36-51.

61. Teichert, A., Chemische und biologische Untersuchungen von Inhaltsstoffen aus Pilzfruchtkörpern der Gattungen Cortinarius und Hygrophorus. 2008, Martin-Luther Universität HalleWittenberg: Halle (Saale). p. 133.

62. Butzbach, K., \& Epe, B. (2013). Photogenotoxicity of folic acid. Free Radical Biology and Medicine, 65, 821-827.

63. Wolnicka-Glubisz, A., et al. (2020). Analysis of photoreactivity and phototoxicity of riboflavin's analogue 3MeTARF. Journal of Photochemistry and Photobiology B: Biology, 205, 111820.

64. Schultz, K. J., et al. (2014). UVA-Photoactivated Riboflavin Treatment of Vaginal Cells Derived from Pelvic Organ Prolapse cases. Gynecologic and Obstetric Investigation, 77(2), 100-103.

65. Gill, M., \& Steglich, W. (1987). Pigments of fungi (Macromycetes). Fortschritte der Chemie organischer Naturstoffe, 51, $1-317$.

66. Besl, H., Bresinsky, A., \& Kronawitter, I. (1975). Notizen über Vorkommen und systematische Bewertung von Pigmenten in Höheren Pilzen (I). Zeitschrift für Pilzkunde : ZfP, 41, 81-98.

67. Iten, P. X., et al. (1984). Isolierung und Struktur von Pteridinen (Lumazinen) aus Russula sp. (Täublinge; Basidiomycetes). Helvetica Chimica Acta, 67(2), 550-569.

68. Weiß, D., \& Brandl, H. (2013). Fluoreszenzfarbstoffe in der Natur. Chemie in unserer Zeit, 47(2), 122-131.

69. Cheng, L., et al. (2009). The examination of berberine excited state by laser flash photolysis. Spectrochimica Acta Part A: Molecular and Biomolecular Spectroscopy, 73(2), 268-272.

70. Redmond, R. W., \& Gamlin, J. N. (1999). a compilation of singlet oxygen yields from biologically relevant molecules. Photochemistry and Photobiology, 70(4), 391-475.

71. Zhang, F. H., et al. (2016). Isolation and identification of berberine from endophytic fungi HL-Y-3. Zhongguo Zhong Yao Za Zhi, 41(16), 2998-3001.

72. Teichert, A., et al. (2008). (Iso)-quinoline alkaloids from fungal fruiting bodies of Cortinarius subtortus. Journal of Natural Products, 71(6), 1092-1094.

73. Diwu, Z., \& William Lown, J. (1994). Phototherapeutic potential of alternative photosensitizers to porphyrins. Pharmacology and Therapeutics, 63(1), 1-35.

74. Cambie, R. C., \& Le Quesne, P. W. (1966). Chemistry of fungi. III . Constituents of Coriolus sanguineus. Journal of the Chemical Society C, 14(1), 72-74.

75. Chung, K. S., Shim, M. J., \& Kim, B. K. (1978). Studies on the constituents of the higher fungi of Korea. XI. An antibiotic component and a sterol of Coriolus sanguineus Fr. Arch. Pharmacal Res, 1(1), 33-40.

76. Dias, D. A., \& Urban, S. (2009). HPLC and NMR studies of phenoxazone alkaloids from Pycnoporus cinnabarinus. Natural Products Communications, 4(4), 489-498. 
77. Gripenberg, J. (1951). Fungus pigment. I. Cinnabarine, a coloring matter from Trametes cinnabarina. Acta Chemica Scandinavica, 5, 590-595.

78. Aulinger, K., Arnold, N., \& Steglich, W. (2000). Metabolites of 2-Aminophenol from Fruit Bodies of Lepiota americana (Agaricales). Zeitschrift für Naturforschung C, 55(5-6), 481-484.

79. Moser, M., Kleine Kryptogamenflora : 2, Pilze, T. b, Basidiomyceten, T. 2 : Die Röhrlinge und Blätterpilze : (Polyporales, Boletales, Agaricales, Russulales)/von Meinhard Moser. 5., bearb. Aufl.. ed, ed. H. Gams. 1983: Stuttgart [u.a.]: G. Fischer. XIII, 533 S., zahlr. Ill., $22 \mathrm{~cm}, 2$ Beil

80. Schlunegger, U. P., Kuchen, A., \& Clémençon, H. (1976). Mycelprodukte höherer Pilze. 1. Mitteilung phenoxazin-derivate in Calocybe gambosa. Helvetica Chimica Acta, 59(4), 1383-1388.

81. Smania, A., Jr., et al. (2003). Toxicity and antiviral activity of cinnabarin obtained from Pycnoporus sanguineus (Fr.) Murr. Phytotherapy Research, 17(9), 1069-1072.

82. Smânia, A., et al. (1995). Antibacterial activity of a substance produced by the fungus Pycnoporus sanguineus (Fr.) Murr. Journal of Ethnopharmacology, 45(3), 177-181.

83. Cooper, P. D. (1966). The inhibition of poliovirus growth by actinomycin $\mathrm{D}$ and the prevention of the inhibition by pretreatment of the cells with serum or insulin. Virology, 28(4), 663-678.

84. Dembitsky, V. M., Gloriozova, T. A., \& Poroikov, V. V. (2017). Pharmacological and predicted activities of natural azo compounds. Natural Products and Bioprospecting, 7(1), 151-169.

85. Gill, M., \& Strauch, R. J. (1984). Constituents of Agaricus xanthodermus Genevier: the first naturally endogenous azo compound and toxic phenolic metabolites. Zeitschrift fur Naturforschung, 39(11-12), 1027-1029.

86. Dong, M., et al. (2015). Red-shifting azobenzene photoswitches for in vivo use. Accounts of Chemical Research, 48(10), 2662-2670.

87. Kellner, S., \& Berlin, S. (2020). Two-photon excitation of azobenzene photoswitches for synthetic optogenetics. Applied Sciences, 10(3), 805.

88. Schmidt, R., et al. (1994). Phenalenone, a universal reference compound for the determination of quantum yields of singlet oxygen $\mathrm{O} 2(1 \Delta \mathrm{g})$ sensitization. Journal of Photochemistry and Photobiology A: Chemistry, 79(1), 11-17.

89. Elsebai, M. F., et al. (2014). Fungal phenalenones: chemistry, biology, biosynthesis and phylogeny. Natural Product Reports, 31(5), 628-645.

90. Inokoshi, J., et al. (1999). Funalenone, a novel collagenase inhibitor produced by Aspergillus niger. The Journal of antibiotics, 52(12), 1095-1100.

91. Park, S. C., et al. (2019). Phenalenones from a marine-derived fungus Penicillium sp. Marine Drugs, 17(3), 176.

92. Nazir, M., et al. (2015). Phenalenones: insight into the biosynthesis of polyketides from the marine alga-derived fungus Coniothyrium cereale. Organic \& Biomolecular Chemistry, 13(29), 8071-8079.

93. Sandoval-Altamirano, C., et al. (2018). Photophysical characterization of hydroxy and ethoxy phenalenone derivatives. Journal of Photochemistry and Photobiology A: Chemistry, 353, 349-357.

94. De Bonfils, P., et al. (2020). Unusual oxidative dealkylation strategy toward functionalized phenalenones as singlet oxygen photosensitizers and photophysical studies. The Journal of Organic Chemistry, 85(16), 10603-10616.

95. Klamann, J. D., Fugmann, B., \& Steglich, W. (1989). Alkaloidal pigments from Lactarius necator and L. atroviridis. Phytochemistry, 28(12), 3519-3522.

96. Wolfender, J.-L., et al. (2019). Accelerating metabolite identification in natural product research: toward an ideal combination of liquid chromatography-high-resolution tandem mass spectrometry and nmr profiling, in silico databases, and chemometrics. Analytical Chemistry, 91(1), 704-742.

97. Willstaedt, H. (1935). Über die Farbstoffe des echten Reizkers (Lactarius deliciosus L.) (I. Mitteil). Berichte der deutschen chemischen Gesellschaft (A and B Series), 68(2), 333-340.

98. Chiang, H.-M., et al. (2010). Photoirradiation of azulene and guaiazulene-formation of reactive oxygen species and induction of lipid peroxidation. Journal of Photochemistry and Photobiology A: Chemistry, 211(2), 123-128.

99. Halbwachs, H., Simmel, J., \& Bässler, C. (2016). Tales and mysteries of fungal fruiting: how morphological and physiological traits affect a pileate lifestyle. Fungal Biology Reviews, 30(2), 36-61.

100. Daniewski, W. M., \& Vidari, G., et al. (1999). Constituents of Lactarius (Mushrooms). In W. A. Ayer (Ed.), Fortschritte der Chemie organischer Naturstoffe/Progress in the chemistry of organic natural products (pp. 69-171). Vienna: Springer.

101. Bergendorff, O., \& Sterner, O. (1988). The sesquiterpenes of Lactarius deliciosus and Lactarius deterrimus. Phytochemistry, 27(1), 97-100.

102. Diaz-Muñoz, G., et al. (2018) Chapter 11-Anthraquinones: an overview, in studies in natural products chemistry. In R. Atta (Ed.) (pp. 313-338) Amsterdam: Elsevier

103. Pankewitz, F., et al. (2007). Anthraquinones as defensive compounds in eggs of Galerucini leaf beetles: Biosynthesis by the beetles? Archives of Insect Biochemistry and Physiology, 66(2), 98-108.

104. Gill, M., et al. (1992). Tetrahydroanthraquinone And Anthraquinone Gentiobiosides From Dermocybe Splendida; The First Anthraquinonoid Disaccharides From Basidiomycetes. Natural Product Letters, 1(3), 187-192.

105. Gill, M., \& Morgan, P. M. (2001). New fungal anthraquinones. ARKIVOC, 7, 145-156.

106. Xia, Q., et al. (2007). Photo-irradiation of Aloe vera by UVAformation of free radicals, singlet oxygen, superoxide, and induction of lipid peroxidation. Toxicology Letters, 168(2), 165-175.

107. Zang, L., et al. (2017). Photophysical properties, singlet oxygen generation efficiency and cytotoxic effects of aloe emodin as a blue light photosensitizer for photodynamic therapy in dermatological treatment. Photochemical and Photobiological Sciences, 16(7), 1088-1094.

108. Comini, L. R., et al. (2017). Parietin: an efficient photo-screening pigment in vivo with good photosensitizing and photodynamic antibacterial effects in vitro. Photochemical and Photobiological Sciences, 16(2), 201-210.

109. Steglich, W., Lösel, W., \& Austel, V. (1969). Pilzpigmente, IV. Anthrachinon-Pigmente aus Dermocybe sanguinea (Wulf, ex Fr.) Wünsche und D .semisanguinea (Fr.). Chemische Berichte, 102(12), 4104-4118.

110. Keller, G (1982) Pigmentationsuntersuchungen bei europäischen Arten aus der Gattung Dermocybe (FR.) WÜNSCHE. Sydowia $35,110-126$

111. Siewert, B., et al. (2019). A convenient workflow to spot photosensitizers revealed photo-activity in basidiomycetes. RSC Advances, 9(8), 4545-4552.

112. Hammerle, F., et al. (2021). Targeted isolation of photoactive pigments from mushrooms yielded a highly potent new photosensitizer: 7,7'-biphyscion. ChemRixv. https://doi.org/10.26434/ chemrxiv. 13721770

113. Meldau, S., Erb, M., \& Baldwin, I. T. (2012). Defence on demand: mechanisms behind optimal defence patterns. Annals of Botany, 110(8), 1503-1514.

114. Nigg, H. N., et al. (1993). Phototoxic coumarins in limes. Food and Chemical Toxicology, 31(5), 331-335. 
115. Menichini, F., et al. (2010). In vitro photo-induced cytotoxic activity of Citrus bergamia and C. medica L. cv. Diamante peel essential oils and identified active coumarins. Pharmaceutical Biology, 48(9), 1059-1065.

116. Pérez-Amador, A. N., \& García-Jiménez, F. (2006). Essential oil and phototoxic compounds in Clibadium surinamense L. and Montanoa grandiflora D.C. (Asteraceae). Phyton International Journal of Experimental Botany, 75, 145-150.

117. Zheng, X., et al. (2018). Biodegradable hypocrellin derivative nanovesicle as a near-infrared light-driven theranostic for dually photoactive cancer imaging and therapy. Biomaterials, 185, 133-141.

118. Matthews, M. R., et al. (2017). Lemons in the Arizona sunshine: the effects of furocoumarins leading to phytophotodermatitis and burn-like injuries. Wounds, 29(12), E118-e124.

119. Mioduszewski, M., \& Beecker, J. (2015). Phytophotodermatitis from making sangria: a phototoxic reaction to lime and lemon juice. Canadian Medical Association Journal, 187(10), 756-756.

120. Torres-Navarro, I., Condiño-Brito, E., \& Botella-Estrada, R. (2018). "Mojito's" phytophotodermatitis, the other "lime" disease. Med Clin (Barc), 151(1), 44.

121. Kornfeld, J. M., \& Edwards, J. M. (1972). An investigation of the photodynamic pigments in extracts of Lachnanthes tinctoria. Biochimica et Biophysica Acta (BBA), 286(1), 88-90.

122. Arnold, N., Bresinsky, A., \& Kemmer, H. (1987). Notizen zur Chemotaxonomie der Gattung Dermocybe (Agaricales) und zu ihrem Vorkommen in Bayern. Zeitschrift für Mykologie, 53(2), 187-194.

123. Zobayed, S. M. A., et al. (2006). Plant-environment interactions: accumulation of hypericin in dark glands of Hypericum perforatum. Annals of Botany, 98(4), 793-804.

124. Ellis, S. M., et al. (1995). Thiarubrines: novel dithiacyclohexadiene polyyne photosensitizers from higher plants. Light-ACTIVATED PEST CONTROL (pp. 164-178). American Chemical Society.

125. Konovalov, D. A. (2014). Polyacetylene compounds of plants of the Asteraceae family (review). Pharmaceutical Chemistry Journal, 48(9), 613-631.

126. Ellis, S.M. (1993). Thiarubrine production in roots and root cultures of Ambrosia chamissonis

127. Cosio, E. G., et al. (1986). Production of Antibiotic Thiarubrines by a Crown gall Tumor Line of Chaenactis douglasii. Journal of Plant Physiology, 124(1), 155-164.

128. Kühner, R. (1978). Les grandes lignes de la classification des Agaricales, Plutéales, Tricholomatales (suite). Publications de la Société Linnéenne de Lyon, p. 325-388

129. Clémençon, H. (1997). Anatomie der Hymenomyceten: eine Einführung in die Cytologie und Plectologie der Krustenpilze, Porlinge, Keulenpilze, Leistlinge, Blätterpilze und Röhrlinge: F. Flück-Wirth

130. Abrahamse, H., \& Michael, R. (2016). Hamblin, new photosensitizers for photodynamic therapy. Biochemical Journal, 473(4), 347-364.

131. Anderson, M. C. (1964). Studies of the woodland light climate: I. the photographic computation of light conditions. Journal of Ecology, 52(1), 27-41.

132. Baldocchi, D. D., Vogel, C. A., \& Hall, B. (1997). Seasonal variation of energy and water vapor exchange rates above and below a boreal jack pine forest canopy. Journal of Geophysical Research: Atmospheres, 102(D24), 28939-28951.

133. Evans, G. C., \& Coombe, D. E. (1959). Hemisperical and woodland canopy photography and the light climate. Journal of Ecology, 47(1), 103-113.

134. Nijssen, B., \& Lettenmaier, D. P. (1999). A simplified approach for predicting shortwave radiation transfer through boreal forest canopies. Journal of Geophysical Research: Atmospheres, 104(D22), 27859-27868.

135. Persson, T. and S.N. Forskningsraad, Structure and function of northern coniferous forests; an ecosystem study. 1980.

136. Jarvis, P., et al. (1976). Vegetation and the atmosphere. In J. L. Monteith (Ed.), Case studies ( p. 171-240)

137. Hofmeister, H. (1997). Lebensraum Wald: Pflanzengesellschaften und ihre Ökologie. Parey: Hamburg.

138. Li, G., et al. (2012). Phaeosphaerins A-F, Cytotoxic Perylenequinones from an Endolichenic fungus, Phaeosphaeria sp. Journal of Natural Products, 75(2), 142-147.

139. Heiser, I., et al. (2004). Fatty acid peroxidation by rubellin B, C and D, phytotoxins produced by Ramularia collo-cygni (Sutton et Waller). Physiological and Molecular Plant Pathology, 64(3), 135-143.

140. Daub, M. E., \& Hangarter, R. P. (1983). Light-induced production of singlet oxygen and superoxide by the fungal toxin, cercosporin. Plant Physiology, 73(3), 855-857.

141. Cavallini, L., et al. (1979). Lipid peroxidation induced by cercosporin as a possible determinant of its toxicity. Chemico-Biological Interactions, 28(2), 139-146.

142. Miethbauer, S., Heiser, I., \& Liebermann, B. (2003). The phytopathogenic fungus ramularia collo-cygni produces biologically active rubellins on infected barley leaves. Journal of Phytopathology, 151(11-12), 665-668.

143. Daub, M. E., \& Ehrenshaft, M. (1993). The photoactivated toxin cercosporin as a tool in fungal photobiology. Physiologia Plantarum, 89(1), 227-236.

144. Kiesslich, T., et al. (2013). A comprehensive tutorial on in vitro characterization of new photosensitizers for photodynamic antitumor therapy and photodynamic inactivation of microorganisms. BioMed Research International, 2013, 840417.

145. You, Y. (2018). Chemical tools for the generation and detection of singlet oxygen. Organic and Biomolecular Chemistry, 16(22), 4044-4060.

146. Hammerschmidt, R. (1999). PHYTOALEXINS: What Have We Learned After 60 Years? Annual Review of Phytopathology, 37(1), 285-306.

147. Shen, Y., Hu, F., \& Min, W. (2019). Raman Imaging of Small Biomolecules. Annual Review of Biophysics, 48(1), 347-369.

148. Marmann, A., et al. (2014). Co-cultivation-a powerful emerging tool for enhancing the chemical diversity of microorganisms. Marine drugs, 12(2), 1043-1065.

149. Eisfelder, I. (1960). Pilzfauna als Wegweiser in der Pilzforschung. Zeitschrift für Pilzkunde, 26, 86-93.

150. Eisfelder, I. (1961). Käferpilze und Pilzkäfer. Zeitschrift für Pilzkunde, 27(2-4), 44-54.

151. Besl, H., \& Blumreisinger, M. (1983). Eignung von Drosophila melanogaster zur Untersuchung der Anfalligkeit hoher Pilze gegenuber Madenfrass. Zeitschrift fur Mykologie, 49, 167-172. 